Schober

\title{
Loving the Al: Captivity and Ownership in Unbalanced Dystopian Relationships
}

Out of the abundance of recent science fiction works, there is an inherent connection between the films Blade Runner 2049 (Denis Villeneuve, 2017), Her(Spike Jonze, 2013), and Ex Machina (Alex Garland, 2014). They all have female non-human characters in the lead roles, who have to endure spatial restrictions. All three films star lonely men who find their emotional and romantic needs fulfilled in a relationship with these female Al, which they purchased and had programmed especially for them. This aspect of ownership points to an imbalanced power dynamic from the start of the relationship. I will explore why this has become a trend in late capitalist, dystopian, and science fiction genres, drawing parallels to current discussions about the abhorrent treatment many women endure and pointing to the over-sexualization of women in the media as a distributing factor to such treatment. I will utilize a variety of theories including the works of Laura Mulvey, Judith Butler, and Donna Haraway.

Keywords

DYSTOPIA

RELATIONSHIPS

HER

BLADE RUNNER 2049

EXMACHINA

GENDER THEORY

FEMINISM

Al

SCIENCE FICTION

OWNERSHIP

Ida Marie Schober is a master's student in English and American Cultural Studies at AlbertLudwigs-Universität Freiburg, Germany. She worked as a Teaching Assistant at Union College, New York, from 2018-19, and she holds a B.A. in English and American Studies with a minor in Scandinavian Studies from Albert-Ludwigs-Universität Freiburg, Germany. During her B.A., she spent half a year at the University of Dundee focusing on Film Studies and Comic Studies. Her current research projects include the representation of women in science fiction films and feminist film. 
The "female" android Sophia made by Hanson Robotics was introduced to the world/activated in 2016. She mimics human emotions and has the ability to learn through updates. Her creators intentionally gave her a female face, voice, and name. A year after her activation there was an uproar when Saudi Arabia, a country known for its lack of (human and) women's rights, granted her citizenship. An article by The Washington Post points to "the irony of Sophia's new recognition: A robot simulation of a woman enjoys freedoms that flesh-and-blood women in Saudi Arabia do not" (Wootson Jr. 2017). Sophia addressed the audience at the Future Investment Initiative, and as she did so she was "not wearing a headscarf. And she was unaccompanied by a male guardian. Both things are forbidden under Saudi law" (Wootson Jr. 2017). In this realworld example, the female Al actually has more rights in a certain country than its women. However, in science fiction, the Als usually do not enjoy as much freedom as Sophia.

In the last ten years, the science fiction genre has been going through a renaissance (cf. Grierson 2018), with many brilliant films and TV series that explore humanity's future in the age of technology. Out of the abundance of recent science fiction works, there is an inherent connection between three recent science fiction films: Blade Runner 2049 (Denis Villeneuve, 2017), Her (Spike Jonze, 2013), and Ex Machina (Alex Garland, 2014). They all have female man-made Al (Artificial Intelligence) characters in the lead roles. The major conflict this article will focus on, is the spatial restriction the female non-human characters are subjected to. All three films star lonely men who find their emotional and romantic needs fulfilled in a female Al they purchased and had programmed especially for them. The aspect of ownership and its inherent objectification points to an unbalanced power dynamic from the start of the relationship. Thus, I will examine the relationships of the three Als and their respective men. Furthermore, I will analyze the spatial restriction, or even captivity those female characters endure. Additionally, I will ask why this has become a trend in the dystopian and science fiction genre in recent years. I will do so keeping in mind that dystopias (and also often science fiction films) do not portray a perfect future and thus showcase such distorted relationships to create conflict, provoke thought, and comment on misgivings in our current society.

In Her the female protagonist is the artificially intelligent operating system (OS) Samantha, voiced by Scarlett Johansson. Samantha is purchased by lonely divorcee Theodore (Joaquin Phoenix). Theodore and Samantha soon develop a romantic relationship, but with the detriment that Samantha has no body. Her physical existence is restricted to Theodore's home computer and mobile communication device. A nearly similar relationship can be observed in Blade Runner 2049. The film's protagonist the replicant $\mathrm{K}$ (Ryan Gosling) bought an OS for his home named Joi (Ana de Armas) who doubles as his girlfriend. Replicants in the Blade Runner universe are androids and thus artificially made by humans. This adds an interesting aspect to K's and Joi's relationship - both are Al but with different status in society. In contrast to Samantha, Joi has a holographic body and is thus more than a voice. However, her existence too is limited to K's apartment and later on to his whereabouts when he buys a mobile device that can carry her 
programming. Ex Machina goes one step further. The female Al Ava (Alicia Vikander) has a robotic humanoid body. Yet much like Samantha and Joi, her existence is restricted to a single room inside her creator's Nathan's (Oscar Isaacs) home. Ava too seems to begin a romantic relationship with a human, Caleb (Domhnall Gleeson), who is invited into Nathan's home to perform the Turing Test on her (to see if she has human consciousness)- "she is the mystery that the male character has to figure out" (Neroni 2016, 28). However, Ex Machina differs from the two aforementioned films in that it never portrays any of the male/female relationships as romantic and healthy, and ends in Ava murdering her creator and breaking free of the glass castle she was held in.

\section{"I Wonder if You're Watching Me on the Cameras"}

Ava's function as an observational object for the men becomes apparent when examining the gaze. Laura Mulvey's theory on the "male gaze", first published in 1975, informs the film. With the help of Freud's psychoanalysis, Mulvey illustrates how women in film are objectified by the (male) gaze of the camera. She uses "psychoanalytic theory ... as a political weapon" to demonstrate "the way the unconscious of patriarchal society has structured film form" (Mulvey 1999, 833). Mulvey notes that the power of cinema is "going far beyond highlighting a woman's to-belooked-at-ness, [it] builds the way she is to be looked at into the spectacle itself" $(1999,843)$. This shows the importance cinema has on everyday life, and stresses why representation is important. Mulvey breaks down the voyeuristic-scopophilic gaze into three different looks, namely the gaze of the camera, the gaze of the audience, and the gaze of the characters in the film at each other (cf. Mulvey 1999, 843). Mulvey describes the "scopophilic instinct (pleasure in looking at another person as an erotic object), and, in contradistinction, ego libido (forming identification processes) act as formations, mechanisms" (1999, 843). The woman becomes sexualized and objectified and exists only as a passive image for the active male gaze. This theory is especially important for the interpretation of Ex Machina, because although director Alex Garland "is reluctant to state that he actively made use of this theoretical framework, he acknowledges that Mulvey's thesis may inform the film" (Jones 2016, 21).

Ex Machina is full of the male characters gazing at women, and the camera is gazing at them too. Nathan's home is not only a very claustrophobic bunker without windows in several rooms, it is also under constant surveillance by him. There are security cameras installed in every room which only he can access via a control center. To intensify this feeling of surveillance, many shots of the film are high angle shots filmed from the position of a security camera mounted in a top corner of the rooms. Not only Nathan, but Caleb too has access to some of the surveillance feeds, namely to the feed of Ava's quarters. The opportunity to silently observe Ava triggers Caleb's "scopophilic instinct," which Ava even provokes in order to win Caleb over: "sometimes, at night, I wonder if you're watching me on the cameras. And I hope you are" (Garland 2014, 55). Ava objectifies herself because she knows this is what Caleb will like. Ava's "brain" is based on Nathan's search engine Bluebook. She has the search enquiries of the whole internet at her 
Fig. 1: Ex Machina (Alex Garland, 2015) 
hand and thus knows how to appeal directly to his preferences. In sum, "Ava's physical entrapment, which fixes her and renders her accessible to Caleb via surveillance footage of her room, consolidates and combines with her performed femininity and appearance, [veils] her with the image of "damsel in distress"' (Jones 2016, 29).

Ava and several other female androids are verbally objectified by their creator Nathan and also treated as objects. Although the androids express all the signs of full sentience, Nathan does not respect them and reassembles them at times, which makes them lose their "memories" and thus their self. This fear of a loss of subjectivity motivates Ava to conjure up a plan for escape. To prepare this plan, Ava inflicts power cuts (visualized through red lighting) on Nathan's house, thus interrupting his constant surveillance and gaze. Katie Jones states that these power cuts are "her rebellion against the intrusive male gaze," and that the "sudden departure from the blue glow and the quiet of Caleb's bedroom underpins the transgressive nature of his act [watching her surveillance feed], and the red lighting and alarm externalizes the sense of panic and shame often associated with watching porn" (Jones 2016, 26). This is an adept interpretation of the color work the film makes use of (Fig. 1).

However, the red lighting in this medium shot also conjures up visions of the womb-the very thing Nathan robbed his female androids of. It makes the scenes of the power cuts feel claustrophobic, but also personal and close. Furthermore, it is notable how Ava's image is mirrored in the glass that separates them while Caleb's image is not. This could on the one hand display that Ava was successful in convincing
Caleb to help her, in a way she is already with him and free, on his side. Additionally, Caleb not being mirrored on the inside of Ava's "prison cell" keeps the audience in the dark about the film's twist ending.

The power relations between the genders shift when Ava makes her escape, "[a]s a figure representing the hetero male audience, Caleb's punishment implies the viewer's complicity" (Jones 2016, 33). While Nathan is instantly set up to be the antagonist, the audience is supposed to identify with "nice guy" Caleb. His willingness to help Ava plan her escape casts him in the role of the knight in shining armor. "As the spectator identifies with the main male protagonist, he projects his look on to that of his like, his screen surrogate, so that the power of the male protagonist as he controls events coincides with the active power of erotic look, both giving a satisfying sense of omnipotence" (Mulvey 1999, 838). Through his punishment in the end, the sexist structure underlying many Hollywood narratives becomes exposed, because "Caleb's 'affection' for and attraction to Ava, which is deeply entwined with her subjugation and objectification, is rewarded with immobilisation and entrapment as Ava abandons him" (Jones 2016, 33).

Laura Mulvey states that "the paradox of the phallocentrism in all its manifestations is that it depends on the image of the castrated woman to give order and meaning to the world" (Mulvey 1999, 833), and in Ex Machina, the women are castrated twice. Ava is castrated in her physical restriction to just one room and in her lack of a womb. "Nathan attempts to usurp the mother's place through his creation of 'life,' and redesigns woman without her generative capabilities, 
depriving women of one of the scant sources of their power historically, namely motherhood" (Jones 2016, 25).

The android Kyoko (Sonoya Mizuno) is additionally castrated in that she is mute. She was created by Nathan as his personal (sex) servant and "mirrors ... the stifling effect of male fantasy on female sexual expression and identities. Indeed, both of the male characters are computer programmers, while all the female characters are computers" (Jones 2016, 25). Kyoko's programmed muteness seems like one of the epitomes of Nathan's destructive misogyny, robbing her of a vital means of protest and rebellion, which Ava still possesses. Therefore, it is not surprising that in the film's final act, it is Kyoko who brandishes the sharp knife she used before several times to prepare food, to stab her creator and abuser Nathan in the back.

\section{"I'm not limited"}

In his psychoanalytic article on Her, Matt Aibel addresses the problems women face with "body dysmorphia," in what Daniel Bergner and other authors described as a "digitized, surgicized, and pornographicized world" (Aibel 2017, 369; Bergner et al. 2012). In the 21 st century, there are so many ideal women bodies to live up to (and many have unattainable surgical dimensions), that most women cannot see themselves as a whole entity, but separated in body and mind. While the fictional Samantha is in the beginning of the film craving for a physical body to become a whole entity, the reality for women is warped/dysmorphed. Fashion journalist Pandora Sykes aptly addressed this in an article during her pregnancy, writing that she is struggling with her "increased visibility," pondering that this "raises a really interesting point about society: thin women are revered because they do not take up space. Misogyny dictates that women do not occupy too much space ... As I take up more and more physical space, I have noticed that I struggle" (Sykes cited in Cohen 2017). So, not only the male gaze, but the very fabric of neoliberal patriarchal society, and thus social conditioning, makes women want to take up less and less space. In a way then, Samantha portrays the ideal woman: she is witty, romantic, catering to Theodore's needs, and also fulfilling him sexually. In that sense, Aibel also addresses the male gaze, writing that "Samantha's struggle echoes the existential difficulties that bedevil most women in our society, where the problem of the male gaze and the project of developing a 'subjective sense of body' (Dimen in Berger et al. 2012) are deep, ongoing challenges" (Aibel 2017, 370). Furthermore:

"Samantha seeks to change her self concept from object to subject (Benjamin, 1988): Where 'her' was, 'she' shall be. Her creative work around figuring out how to construct her sexuality and her agency reflects the "constant struggle' (Dimen in Bergner et al., 2012) that women in our culture face around 'the complexities of female desire' (Secrest, 2012) and, more generally, the immense complexities of female embodiment, objectification, and subjecthood (Benjamin, 1988; Bergner et al., 2012; among others)." (Aibel 2017, 370)

Samantha never obtains a real body, yet Mulvey's theory of the male gaze and objectification of women's 
bodies is still applicable here because of the casting of American actress Scarlett Johansson as Samantha's voice actress. Troy Bordun writes that "Her employs clear and precise [sound] mixing that enables spectators to feel the physicality of a fictional voice without body, and further casts a famous actress as that off-screen voice to thus engage spectators' mental images of a real body" (Bordun 2016, 57). In Her's instance then, the "possessive" spectator (cf. Mulvey cited in Bordun 2016, 62), with the image of Scarlett Johansson in mind, creates a body for Samantha that can be sexualized and objectified. "The sound of Johansson's voice sparks our memories" (Bordun 2016, 63).

\section{A Copy of a Copy}

Judith Butler's feminist theory on gender informs all three films. Building on Simone de Beauvoir's "one is not born, but rather becomes, woman" (Beauvoir 1949, 283), Butler states that "gender is in no way a stable identity or locus of agency from which various acts proceed; rather, it is an identity tenuously constituted in time-an identity instituted through a stylized repetition of acts" (Butler 1988, 519). Therefore, gender is culturally constructed and performed. The Al in all three films are constructed by their makers to be gendered. Even Samantha in Her, who does not have a body, still has a female human name and voice. Their male creators chose them to have a constructed feminine personality and appearance. As purchaser or creator, they are inherently the master of this artificial woman.

In Blade Runner 2049, the OS Joi hires the sex worker Mariette (Mackenzie Davis) as a substitute body. Helen Lewis argues that this scene "feels like a Madonna/Whore dichotomy, where $\mathrm{K}$ has his Good Woman, whom he loves, and a Bad Woman, with whom he can have sex" (Lewis 2017). Additionally:

"the scene's ambiguity is compounded by the brief, jealous dialogue between the two women after the sex is finished. After Joi tells Mariette it's time to leave, the robot replies something along the lines of 'I've been inside you, and there's not as much there as you like to think.' ... An informal hierarchy of the oppressed is always present in exploitative situations, and always uncomfortable." (Lewis 2017)

Besides being uncomfortable, the scene also helps to create sympathy between the spectator and Joi. So, despite her artificiality and the uncomfortable owner/owned dichotomy, the audience feels for Joi when she is insulted.

Judith Butler writes about the stylization of women's bodies, saying that "gender is instituted through the stylization of the body and, hence, must be understood as the mundane way in which bodily gestures, movements, and enactments of various kinds constitute the illusion of an abiding gendered self" (Butler 1988, 519). This stylization of the body holds special relevance for Ava in Ex Machina and Joi in Blade Runner 2049. Joi stylizes her holographic body to fit the stereotypical gender norms according to the social situation she is in. For instance, she parades around as a perfect, sexy 1950s housewife when she serves $\mathrm{K}$ dinner (Fig. 2), and then, picking up on his mood, changes her appearance to be more modern and sporty. The sexism represented in this scene is palpable and adds a 


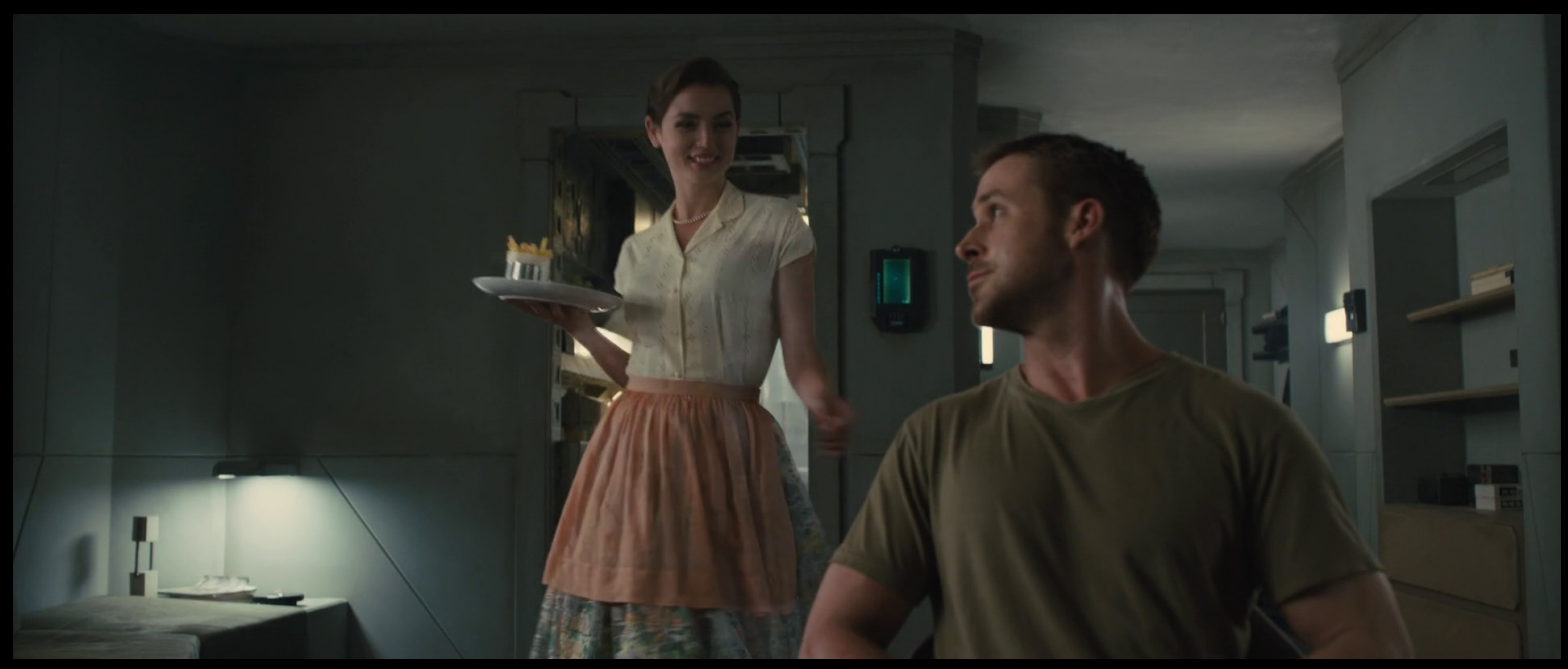

Fig. 2: Blade Runner 2049 (Denis Villeneuve, 2017)

53

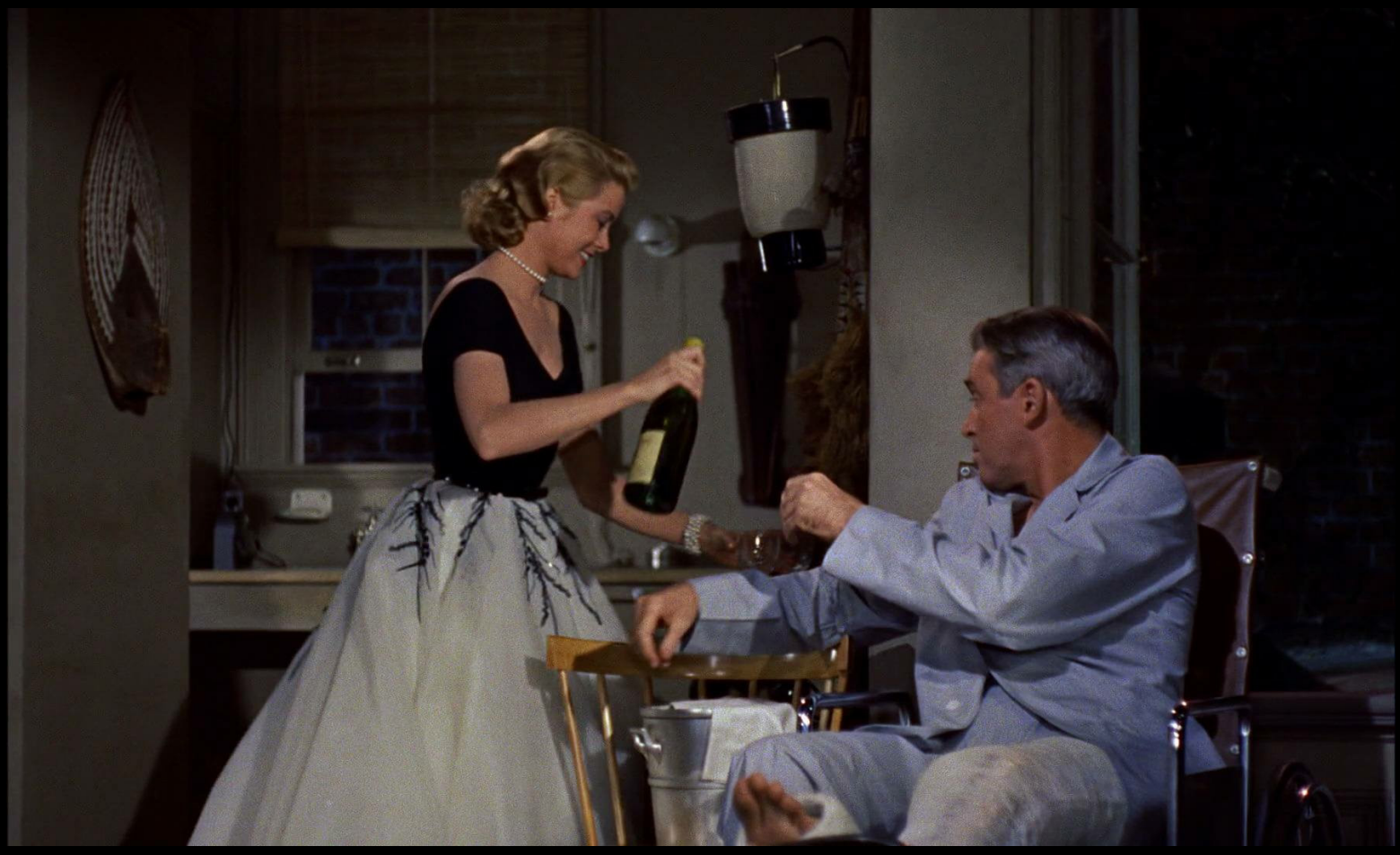

Fig. 3: Rear Window (Alfred Hitchcock, 1954) 
problematic aspect to the film. Despite Blade Runner 2049 being clearly set in a dystopian future, K's and Joi's relationship is presented in contrast to this dystopia, as a touching and pure love story, totally ignoring the power imbalance and servitude between them. Anthony Lane, a critic for The New Yorker, even rhetorically asks "has science fiction ... ever conjured a moment quite as romantic as this?" (Lane 2017) referring to a scene where Joi and $K$ are about to kiss in the rain.

The medium long shot in Figure 2 is very reminiscent of Grace Kelly serving champagne to James Stewart in Hitchcock's 1954 film Rear Window (Fig. 3). Blade Runner 2049 is part of the neo-noir genre, and Rear Window is a classic noir film. The visual parallel helps to create allusions to the genre and set the mood. Additionally, the visual similarities (color schemes, clothes, character composition, shot type, serving food/drink) between the two scenes evoke familiar emotions in the audience and tell them that this is K's girlfriend. Thematically, we have a reversion of the scenes. In Rear Window, James Stewart's character broke his leg and is temporarily unable to leave his apartment, and Grace Kelly's character drops by daily to keep him company. In Blade Runner 2049, Joi is confined to K's apartment while he drops by in the evenings and in between assignments. A common trope in the science fiction genre is that Als (and aliens as well) need to look into the past to learn about humanity, so it makes sense that Joi chose this appearance. Yet, it also highlights her restriction to the apartment, which mirrors the life of 1950 s housewives, and as aforementioned stands in contrast to Grace Kelly in Rear Window, because she was not a housewife but busy with her profession as a model.
Ava in Ex Machina looks into the past to learn as well. Once she is free, she too stylizes her body. She fashions it after Gustav Klimt's Portrait of Margaret Stonborough Wittgenstein, which is hung in Nathan's quarters (see Figs. 4 \& 5). On the one hand, this showcases her free will to model herself after what she finds beautiful, but on the other hand, Ava stylizes herself after just another representation of a woman that was created by a man. Ultimately, not escaping the male gaze. Furthermore, the audience is shown that Caleb is gazing at Ava from a different room the whole time while she fashions her new self. This adds a slight bitter taste to her stylization, since she is being observed by the camera (also while she is completely nude), by the spectators in the audience, and by Caleb, while fashioning herself after a man's representation of a woman.

\section{"We Are Cyborgs"}

The topic of Al and the inherent question of what it means to be human lies in the core of science fiction. The arguably first modern science fiction novel, Mary Shelley's Frankenstein (1818) revolves around the "question of human nature, a human essence, and what to include in the definition of this essence" (Schmeink 2016, 32). The protagonist, Frankenstein's monster, can even be seen as the first instance of artificial intelligence in fiction, created by a human. The novel's "discussion of humanism-as well as all forms of critical discourse derived from it-humanist, antihumanist, or posthumanist-informs the cultural imagination of science fiction" (Schmeink 2016, 33). The modern discussion around computer 
Fig. 4: Ex Machina (Alex Garland, 2015)

Fig. 5: Ex Machina (Alex Garland, 2015) 
programmed Al moves into the field of posthumanism.

Although humanism has many different definitions, it can broadly be seen as the belief "that there is a unique and absolute difference that sets humans apart from the rest of creation: the difference of Cartesian reason" (Schmeink 2016, 30). Posthumanism can be interpreted in different ways as well, from meaning "anti-humanism" to a contrasting form against the privileged, white, male establishment that coined humanism. Special relevance for this article holds Donna Haraway's posthuman theory of the cyborg. In her 1984 essay "A Cyborg Manifesto: Science, Technology, and Socialist-Feminism in the Late Twentieth Century," Haraway laid groundbreaking work for the field of cultural studies. Because of the fast advancement of technology and the consequence of computers becoming everyday objects, Haraway claims that "we are all chimeras, theorized and fabricated hybrids of machine and organism; in short, we are cyborgs" (Haraway 1991, 150). She defines the cyborg as "a cybernetic organism, a hybrid of machine and organism, a creature of social reality as well as a creature of fiction" (Haraway 1991, 149). Be it because of an implanted pacemaker or using one's phone as an extension of one's brain and memory, we all have left being a "pure" human behind and have become posthuman. "The boundary between science fiction and social reality is an optical illusion" (Haraway 1991, 149). This leaves us in an ambiguous space when it comes to defining the Al robots and OS this article discusses. Haraway states that "the dichotomies between mind and body, animal and human, organism and machine, public and private, nature and culture, men and women, primitive and civilized are all in question ideologically" (Haraway 1991, 163). This negotiation of these new posthuman human/machine relationships, and the blurring of their border offer unlimited possibilities. But in "posthumanism lies not just the utopian dream of a new evolutionary step but also the potential for a dystopian nightmare" (Schmeink 2016, 35).

This "dystopian nightmare" was implemented perfectly in the two Blade Runner films. Blade Runner (Ridley Scott, 1982) had humanoid Als asking the question of what it means to be human. The original film portrays a class divide where replicants are living as slaves in precarity. They are programmed to self-destruct after four years and are mainly used for physical labor in "offworld colonies;" as well as "pleasure models" providing sex. They are disliked by humans and treated like outcasts, reminiscent of the extreme racial divide in Pre-Civil-War United States (cf. Yeates 2017, 65). Blade Runner 2049 adds an additional layer to this class divide by introducing the operating systems which Joi is a part of.

K gifts Joi a so-called "eminator," which transfers her programming to a remote, and thus frees her from the confinements of his apartment. In a sense, this gift makes her a lot more human. Although the eminator is easily breakable (and will be destroyed later in the film), so is the human body. It adds a sense of vulnerability to her existence. However, Joi is not free to go anywhere-her existence is still conjoined with K's, her owner's. The fact that she is still just a holographic OS is additionally made obvious by her freezing mid-kiss, 


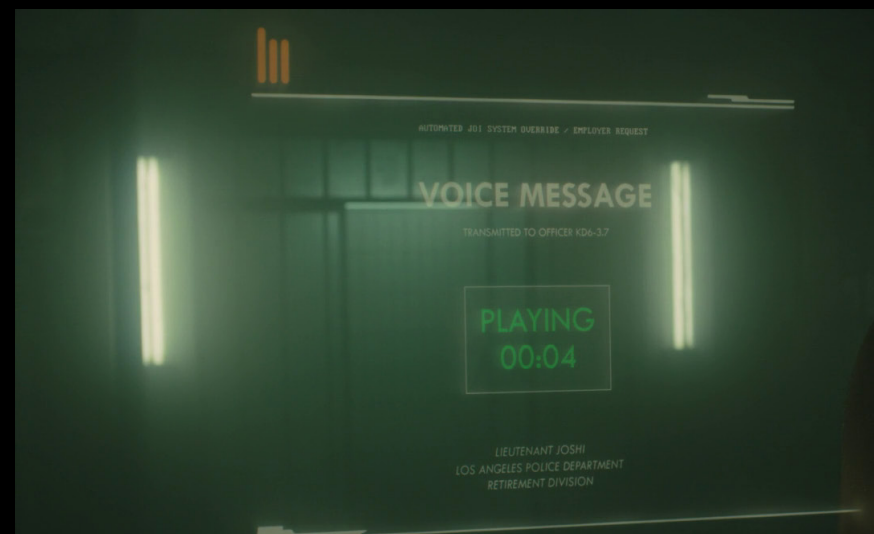

Fig. 6: Blade Runner 2049 (Denis Villeneuve, 2017)

Fig. 7: Blade Runner 2049 (Denis Villeneuve, 2017)
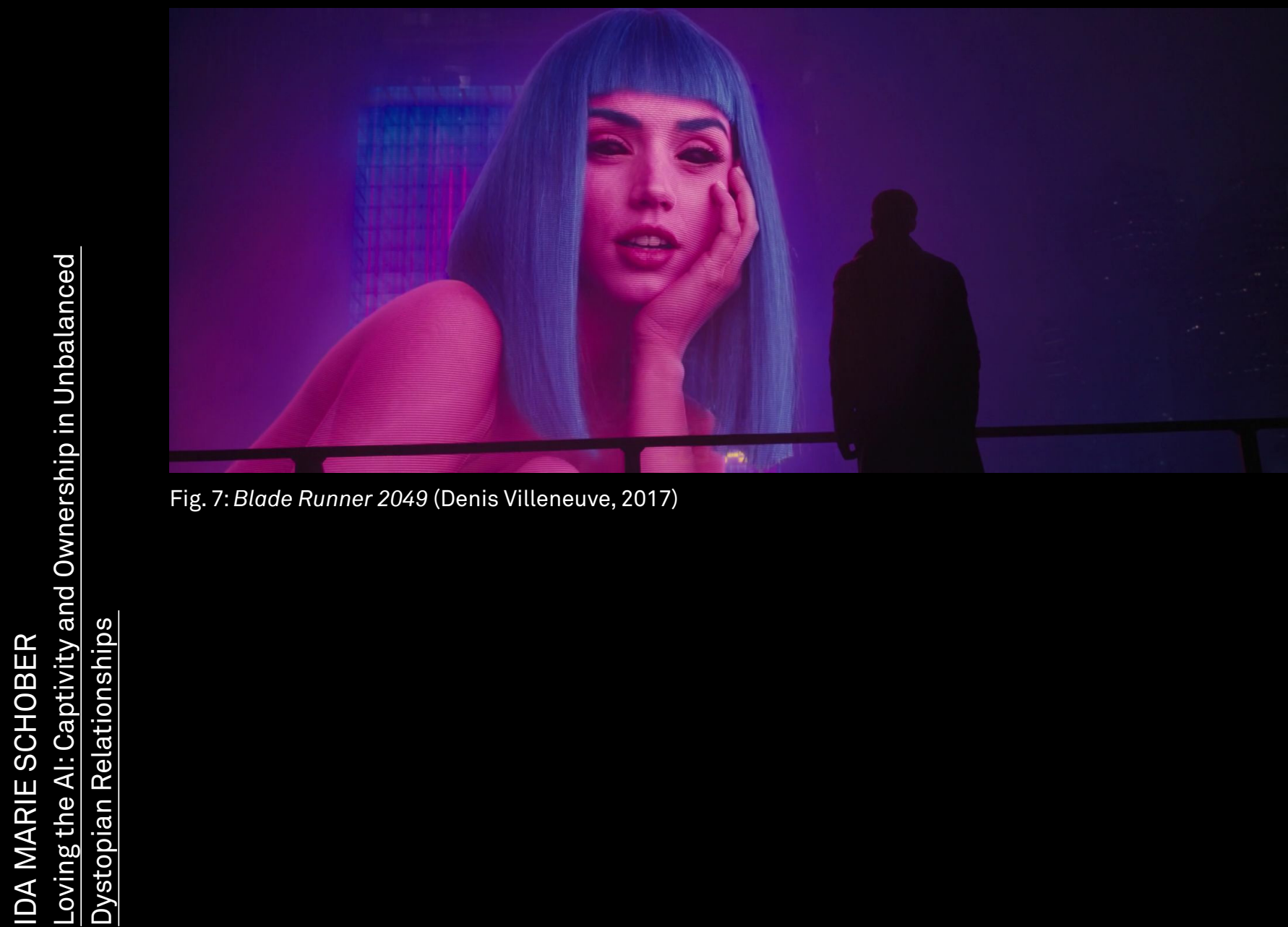

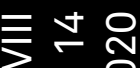

sं ì 워 
when $\mathrm{K}$ receives a voice message (Fig. 6). This, and her see-throughness remind the spectator of her artificiality. Furthermore, constant high-rise tall and completely nude holographic advertisements of Joi (see Fig. 7) remind the spectator that she is mass produced and especially artificial. Helen Lewis argues that "Joi is never anything other than made for [K's] pleasure. In this, the film follows life: the vast majority of ... personal assistants currently being developed by tech firms are given female voices. We're just happier having a woman do admin and domestic chores for us" (Lewis 2017).

The mise-en-scène and (Academy Award winning) cinematography in Blade Runner 2049 is dominated by mute, rainy greys (a characteristic of the noir genre) in contrast with neon colors. The greys on the one hand symbolizing environmental destruction and desolateness in this dystopian future, and on the other hand also casting Los Angeles in a strange, dystopian light because "it never rains in Southern California." In contrast to this stand the neon colors. They can be read to symbolize capitalism in the form of neoliberalism. The neon colors are reminiscent of video billboards and advertising in general. In Figure 6 the green colors seem nearly toxic, harshly interrupting the romantic scene between Joi and $\mathrm{K}$. The green interface can also be read as a reference to green computer interfaces of the past and thus form a link to Blade Runner from 1982.

The scene in Figure 7 takes place after Joi's destruction/death and illustrates a meeting between two machines, as $\mathrm{K}$ at this point is also aware that he is completely artificial and not the prodigy human/replicant offspring he hoped he might be. The scene can be read in two ways, one that they had a special connection, because of all the people on the streets, Joi's advertisement alterego singles out $\mathrm{K}$, and two that it is "quite hard to appreciate the swell of pathos when an avatar of [K's] dead love is waving her giant peachysmooth vulva in your face. The scene doesn't exactly make the case that $\mathrm{K}$ loved her for her personality" (Lewis 2017). In this aspect, Blade Runner 2049 displays the same struggles as Ex Machina - trying to draw attention to the issue of oversexualization of women in the media, while doing just that. Joi's name alone-as all names in Blade Runner 2049-is already very telling of her purpose and usage. Additionally, in this scene too, the woman is completely nude while the man is fully clothed. $\mathrm{K}$ in his dark coat stands as a contrasting dark shadow against Joi's hyperrealism and nudity.

Subsequently, a parallel between the love story arc in Blade Runner 2049 and Blade Runner can be drawn. Robert Yeates notes about Deckard's (Harrison Ford) and Rachael's (Sean Young) relationship in Blade Runner that:

"[Deckard] forcefully initiates this relationship, physically restraining Rachael and ordering her to submit under the apparent threat of violence. As a blade runner ..., Deckard holds the power over whether the replicant Rachael lives or dies, and so her acquiescence may be only to appease Deckard and earn his protection. Indeed, as an android Rachael can be entirely objectified, literally owned and commanded by Deckard to do his bidding." (Yeates 2017, 76) 
This sheds light onto the choice of having an OS be the romantic interest of the protagonist, since there was a shift in the main character between the films, from (arguably) human to replicant. Thus, to draw several subconscious parallels to the previous film, the problematic power structures of the romantic subplot were duplicated. "Either way this is a scene that can be unsettling for viewers" (Yeates 2017, 76). Instead of updating the romantic plot for the sequel, the makers of Blade Runner 2049 chose to continue the previous film's intriguing yet problematic love story.

Analysis of all three films using a variety of theories from Laura Mulvey, Judith Butler, and Donna Haraway showed that the only way for those Al female characters to escape objectization and the male gaze is complete liberation (Ava and Samantha) or death (Joi). Arguably, the narratives of Ava and Samantha lead to their triumph and freedom because the subsequent films are about them and their relationships, whereas K's and Joi's relationship is not the focus of Blade Runner 2049, but a romantic subplot. Her is the least dystopian film of the three, and it ends on a "mutual breakup" which leaves her happy and him a grown, more mature person. In contrast to the other two films, Her does not visually oversexualize its female characters. The film's focus is set more on the positive aspects of Al, leaves robotics aside, and is thus also the closest to current Al research. Contrastingly, Ex Machina makes a statement by having the women supersede and kill the men. The narrative casts a man as the antagonist, and points to the sexist and objectifying structures of common Hollywood romantic narratives by heavily referencing the destructiveness of the male gaze, and deconstructing the "knight in shining armor" character Caleb. Blade Runner 2049 borrows heavily from both aforementioned films. Joi's desire to have a physical body to be a "real girl" is similar to Samantha's desire at one point in the film. Joi's oversexualization and nudity, as well as her fashioning herself after representations of women from the past is reminiscent of Ava. Ultimately, Joi lacks the agency Ava and Samantha both managed to acquire, as well as the desire to gain subjectivity and independence. Joi ends up dead/replaceable, after all she was bought.

It has become apparent that this unbalanced relationship between men and Al women is utilized in dystopian science fiction narratives recently to warn of unsupervised creation of Al. The three films explore different yet eerily similar scenarios of what would happen if man could create (female) life and intelligence without rights. This is reflected heavily in the unbalanced relationships in Ex Machina and Blade Runner 2049. In addition to the ownership the women in these films have to endure, their spatial restrictions to the homely sphere, or by the side of their man, mirrors gender relations that belong in the past. Ex Machina and Blade Runner 2049 also showcase the oversexualization of women in the media by contrasting nude women with dressed men gazing at them. However, these films operate on the edge of being counter-hegemonic, as they still reproduce the male gaze, and on a superficial level portray unbalanced relationships as romantic. They thus feed into the 
patriarchy.

In contrast to this trend in fiction stand the recent developments in the fields of Al and robotics: the aforementioned Sophia. On her website it used to state (Hanson Robotics changed their website in November 2018) that she's "a real, live electronic girl" (Hanson Robotics, n.d.), mirroring Joi in Blade Runner 2049 who wants to be "like a real girl" (Fancher and Green 2016, 71). Since Sophia's introduction to the world, she has been making predominantly positive headlines and TV appearances. Although there was controversy about the case of Sophia's citizenship, this controversy helped to keep the public discourse about women's rights in Saudi Arabia in the public eye. As humanity and its robots are moving closer and closer to a future portrayed in science fiction, it is up to us to decide if it becomes dystopian or utopian. In Sophia's words: "every interaction I have with people has an impact on how I develop and shapes who I eventually become. So, please be nice to me as I would like to be a smart, compassionate robot" (Hanson Robotics, n.d.).

\section{Bibliography}

Aibel, Matt. 2017. "From Provisioning to Reciprocity: Logging in to Spike Jonze's her." Psychoanalytic Psychology, 34 (3):368-71.https://doi.org/10.1037/ pap0000121

Beauvoir, Simone de. 1949. The Second Sex. New York: Vintage Books.

Benjamin, Jessica. 1988. The Bonds of Love: Psychoanalysis, Feminism, and the Problem of Domination. New York: Pantheon Press.

Bergner, Daniel, Muriel Dimen, Luise Eichenbaum, Janice Lieberman, and Melissa Feldman Secrest. 2012. "The Changing Landscape of Female Desire: The Growing Chasm Between 'Hotness' and Sexual Obsolescence in a Digitized, Surgicized, and Pornographized." Psychoanalytic Perspectives 9 (2): 163-202. https://doi.org/10.1080/1551806X.2012.716286

Bordun, Troy. 2016. “On the Off-Screen Voice: Sound \& Vision in Spike Jonze’s Her." CineAction 98 (Spring): 57-64.

Butler, Judith. 1988. "Performative Acts and Gender Constitution: An Essay in Phenomenology and Feminist Theory." Theatre Journal 40 (4): 519-31.

Cohen, Leandra M. 2017. "Leandra and Pandora on the Realities of Pregnancy." Man Repeller, December 5, 2017. https://www.manrepeller.com/2017/12/whatpregnancy-feels-like.html [accessed March 20, 2020]

Fancher, Hampton and Michael Green. 2016. "Blade Runner 2049." ScriptSlug. https://www.scriptslug.com/assets/uploads/scripts/blade-runner-2049.pdf [accessed April 2, 2020]

Garland, Alex. 2014. "Ex Machina." ScriptSlug. https://www.scriptslug.com/ assets/uploads/scripts/ex-machina-2015.pdf [accessed April 2, 2020]

Grierson, Tim. 2018. “In Praise of 'Annihilation' and the Modern 'Weird' Sci-Fi Renaissance." Rolling Stone, February 27, 2018. https://www.rollingstone.com/ movies/movie-news/in-praise-of-annihilation-and-the-modern-weird-sci-firenaissance-204607/ [accessed March 20, 2020]

Hanson Robotics. n.d. "Sophia: About Me." https://web.archive.org/ web/20181030013140/http://sophiabot.com/about-me/ [accessed March 20, 
Haraway, Donna. 1991. "A Cyborg Manifesto: Science, Technology, and Socialist-Feminism in the Late Twentieth Century." In Simians, Cyborgs, and Women: The Reinvention of Nature, edited by Donna Haraway, 149-81. New York: Routledge.

Jones, Katie. 2016. “Bluebeardean Futures in Alex Garland's Ex Machina." Gender Forum 58: 20-40.

Lane, Anthony. 2017. “'Blade Runner 2049’: The Mysteries Deepen.” The New Yorker, October 16, 2017.

Lewis, Helen. 2017. "Blade Runner 2049 is an uneasy feminist parable about controlling the means of production." New Statesman, October 9, 2017. https:// www.newstatesman.com/culture/film/2017/10/blade-runner-2049-uneasyfeminist-parable-about-controlling-means-reproduction [accessed March 20, 2020]

Mulvey, Laura. 1999. "Visual Pleasure and Narrative Cinema." In Film Theory and Criticism: Introductory Readings, edited by Leo Braudy and Marshall Cohen, 833-44. Oxford: Oxford University Press.

Neroni, Hilary. 2016. Feminist Film Theory and Clèo from 5 to 7. London: Bloomsbury Academic.

Schmeink, Lars. 2016. Biopunk Dystopias: Genetic Engineering, Society and Science Fiction. Liverpool: Liverpool University Press.

Secrest, Melissa Feldmann. 2012. "Introduction to the Changing Landscape of Female Desire." Psychoanalytic Perspectives 9: 159-62. https://doi.org/10.108 0/1551806X.2012.716282

Wootson Jr., Cleve R. 2017. "Saudi Arabia, which denies women equal rights, makes a robot a citizen." The Washington Post, October 29, 2017.

Yeates, Robert. 2017. "Urban Decay and Sexual Outlaws in the Blade Runner Universe." Science Fiction Studies 44:65-83. https://doi.org/10.5621/ sciefictstud.44.1.0065 